\title{
Toward the Design of a Cognitive Tutor for Algebra with Gamification: A Survey of State-of-the-Art
}

\author{
Blanca-Estela Pedroza-Méndez ${ }^{1}$, Juan-Manuel González-Calleros ${ }^{1}$, \\ Josefina Guerrero-García ${ }^{1}$, Carlos-Alberto Reyes-García ${ }^{2}$ \\ ${ }^{1}$ Benemérita Universidad Autónoma de Puebla, Puebla, México \\ ${ }^{2}$ Instituto Nacional de Astrofísica Óptica y Electrónica (INAOE), Sta. María Tonantzintla, \\ Puebla, México \\ \{blancaestela.pedroza, jumagoca78, joseguga01\}@gmail.com, \\ kargaxxi@inaoep.mx
}

\begin{abstract}
A cognitive tutor is a kind of intelligent tutoring system, which is particularly focused on providing individualized support for the improvement of complex cognitive abilities through the practice of problem resolution. The development of a cognitive tutor involves the analysis of diverse strategies and theories related both to computer science and to pedagogy, as well as the analysis of models related to the discipline in which the tutor will be used. In this paper, an analysis of the state of the art of the topics that have been identified as necessary for the design of a cognitive tutor with gamification to support students with the solving of algebraic problems is conducted. Whenever we talk about an intelligent tutor, models capable of simulating decision making, such as fuzzy models, are required; thus, they are also considered for this analysis. Additionally, comparison tables that allow the identification of opportunity areas for the development of solutions to problems that haven't been thoroughly covered in the literature are presented.
\end{abstract}

Keywords. Fuzzy cognitive maps, solving algebra problems, cognitive tutors.

\section{Introduction}

Intelligent Tutorial Systems (ITS) are computer systems designed to facilitate and help a student with the task of learning. They possess experience, for they know the subject to be taught (domain knowledge) and how to teach (pedagogic knowledge), as well as having means to obtain information from the student $[1,2]$. A Cognitive Tutor (CT) is a type of ITS with a long-time proven efficacy. Its efficacy is based on its capacity to provide individualized support for the learning of complex cognitive abilities through the practice of problem solving, since they individualize education 
through the selection of problems based on a model of the student's current knowledge status, which is updated constantly [3].

One way to complement the design of an intelligent tutorial is by adding gamification features, which consists in the application of principles and elements of game playing in a learning environment with the purposes of influencing behavior, increasing motivation, and promoting student participation [4]. The design and development of a cognitive tutor for helping students develop their skills in algebraic problems solving requires, in its initial steps, the identification of the topics required as a basis, as well as a means to organize all the information required. In order to do this, the 7-module architecture presented by González, Mora \& Toledo [1] allows us to classify and construct the state of the art of some of the theories and concepts required for the design and implementation of a cognitive tutor.

This paper is organized as follows: Section 2 provides a brief description of each of the modules of the cognitive tutor and its relation with the main topics and subtopics; In Section 3, some articles related to the main topics are analyzed; and, finally, Section 4 presents, as a result of the analysis, a table in which papers related to intelligent tutorial systems, as well as to one or several of the topics or subtopics covered in Table 1, are classified.

\section{General Description of Cognitive Tutor}

The Table 1 shows a classification of the modules of a cognitive tutor with their corresponding activities, which, in turn, lead to the identification of topics, concepts and/or theories that, for both practical means and the development of the project, are deemed to be related with the implementation of each module. For example, within the student model module, the student model, the cognitive load theory, and assessment or evaluation, are considered necessary subjects. The student model, as a topic, is important due to the need to identify student preferences throughout the learning process. According to Chrysfiadi et al. [5] it is not effective to assume that all students will follow the same educational model. The student model has two information components: basic information, such as personal data for student identification; and information regarding the knowledge level of the student, as well as his/her cognitive and learning skills. These two information components set the pace for relating the student model to his/her learning style and cognitive skills. Thus, they are considered as subtopics of the student model. Furthermore, the theory of cognitive load, including its two effects - "Expertise Reversal", for the student's level of knowledge, and "Worked Examples, for the handling of the characteristics of the problems that will be presented to the student"-, is considered as a pedagogic foundation. Therefore, the way in which the constant evaluation of the student is conducted is also considered a relevant topic for this module and for the following three: the domain model; the tutor model; and the visualization modules. There are different models for problem solving capability evaluation, for this case, a fuzzy logic model, based on Bloom's Taxonomy, is being used. 
Toward the Design of a Cognitive Tutor for Algebra with Gamification: A Survey of State-of-the-Art

Table 1. Description of each module of a cognitive tutor and its related topics.

\begin{tabular}{|c|c|c|c|}
\hline $\begin{array}{c}\text { ITS } \\
\text { MODULE }\end{array}$ & ACTIVITIES [1] & $\begin{array}{l}\text { RELATED TO- } \\
\text { PICS }\end{array}$ & SUBTOPICS \\
\hline \multirow{6}{*}{$\begin{array}{l}\text { STUDENT } \\
\text { MODEL }\end{array}$} & \multirow{6}{*}{$\begin{array}{l}\text { Represents the } \\
\text { cognitive state } \\
\text { of the student. }\end{array}$} & \multirow{2}{*}{ Student model } & Learning styles \\
\hline & & & Cognitive abilities \\
\hline & & \multirow{2}{*}{$\begin{array}{l}\text { Cognitive Load } \\
\text { Theory }\end{array}$} & Expertise Reversal Effect \\
\hline & & & Worked Examples Effect \\
\hline & & \multirow{2}{*}{$\begin{array}{l}\text { Assessment or } \\
\text { evaluation }\end{array}$} & Bloom's Taxonomy \\
\hline & & & Fuzzy Models for evaluation \\
\hline \multirow{6}{*}{$\begin{array}{l}\text { DOMAIN } \\
\text { MODEL }\end{array}$} & \multirow{6}{*}{$\begin{array}{l}\text { - Contains the } \\
\text { representation of } \\
\text { expert } \\
\text { knowledge in } \\
\text { areas related to } \\
\text { evaluation pro- } \\
\text { cesses, teaching } \\
\text { and learning } \\
\text { methodologies. }\end{array}$} & \multirow{2}{*}{ Fuzzy Logic } & Fuzzy Cognitive Maps \\
\hline & & & Neuro - Fuzzy networks \\
\hline & & Algebra Teaching. & 3UV Model (3 uses of the variable) \\
\hline & & \multirow[b]{3}{*}{ Problem resolution } & Heuristics \\
\hline & & & Metacognitive strategies \\
\hline & & & Belief systems \\
\hline \multirow{6}{*}{ TUTOR MODEL } & \multirow{6}{*}{$\begin{array}{l}\text { - Contains infor- } \\
\text { mation to decide } \\
\text { which tasks are } \\
\text { presented to the } \\
\text { student, accord- } \\
\text { ing with the ob- } \\
\text { jectives of } \\
\text { learning the } \\
\text { "domain mod- } \\
\text { ule" }\end{array}$} & Instructional Design & Neuro - Fuzzy network \\
\hline & & Feedback & Fuzzy Cognitive Maps \\
\hline & & \multirow{2}{*}{$\begin{array}{l}\text { Assessment or } \\
\text { evaluation. }\end{array}$} & Bloom’s Taxonomy \\
\hline & & & Fuzzy Models for evaluation \\
\hline & & \multirow[b]{2}{*}{$\begin{array}{l}\text { Human - Computer } \\
\text { Interaction. }\end{array}$} & Gamification \\
\hline & & & Tangible user interfaces \\
\hline \multirow{2}{*}{ AUTHORING } & \multirow{2}{*}{$\begin{array}{l}\text { - Create custom } \\
\text { activities }\end{array}$} & \multirow{2}{*}{$\begin{array}{l}\text { Human - Computer } \\
\text { Interaction }\end{array}$} & Gamification \\
\hline & & & Tangible user interfaces \\
\hline \multirow{3}{*}{ EXECUTION } & \multirow{3}{*}{$\begin{array}{l}\text { - Interaction with } \\
\text { the student } \\
\text { - Knowledge of } \\
\text { the game }\end{array}$} & Feedback & Fuzzy Cognitive Maps \\
\hline & & \multirow{2}{*}{$\begin{array}{l}\text { Human - Computer } \\
\text { Interaction }\end{array}$} & Gamification \\
\hline & & & Tangible user interfaces \\
\hline \multirow{4}{*}{$\begin{array}{l}\text { VISUALIZA- } \\
\text { TION }\end{array}$} & \multirow{4}{*}{$\begin{array}{l}\text { - Learning } \\
\text { analysis. } \\
\text { - Game Feedback. }\end{array}$} & \multirow{2}{*}{$\begin{array}{l}\text { Assessment or } \\
\text { evaluation }\end{array}$} & Bloom's Taxonomy \\
\hline & & & Fuzzy models \\
\hline & & \multirow{2}{*}{$\begin{array}{l}\text { Human - Computer } \\
\text { Interaction }\end{array}$} & Gamification \\
\hline & & & Tangible user interfaces \\
\hline \multirow{3}{*}{$\begin{array}{l}\text { MANAGE- } \\
\text { MENT }\end{array}$} & \multirow{3}{*}{$\begin{array}{l}\text { - Management of } \\
\text { students } \\
\text { - Creation of } \\
\text { groups }\end{array}$} & \multirow{2}{*}{$\begin{array}{l}\text { Human - Computer } \\
\text { Interaction }\end{array}$} & Gamification \\
\hline & & & Tangible user interfaces \\
\hline & & Fuzzy Logic & Fuzzy Cognitive Maps \\
\hline
\end{tabular}

Regarding the domain model module, three topics are considered as fundamental: expert models; algebra teaching; and problem resolution. Expert models are essential and very important for this research because its main objective is related to the implementation of automatized strategies for the proposal of a teaching model through the use of a cognitive tutor. The function of the expert model is to simulate the decision making process that an expert algebra teacher would make, providing the student with problems that correspond to his/her ability for solving them, as well as with suggestions of topics that the student should review. These topics are considered in the tutor model, authorship, and visualization modules. The models used for this decision making process are, precisely, fuzzy cognitive maps which utilizes learning 
techniques, in order to train Fuzzy Cognitive Map and choose appropriate weights for its interconnections [6].

Within the tutor model module, the topics to be considered are: instructional design, automatic feedback, evaluation or assessment, and human-computer interaction. Automatic Feedback is a strategy that complements the evaluation and instructional design activities. It is clear that the domain model and tutor model modules should have constant interaction. Both use fuzzy model; however, in the domain model module they are focused on the analysis of the topics and the algebraic problems using fuzzy cognitive maps, whereas the tutor model module is a fuzzy model for student classification based on his/her cognitive ability for problem solving. The authoring, execution and visualization modules consider topics that have been previously described.

\section{Analysis of the State of the Art}

In order to identify current advances in each of the topics of interest mentioned in Table 1, a review of some related work with these topics is done. The analysis was done considering works mostly from 2012 to date. In each of the subsections of section 3 , some works of each of the topics are described.

\subsection{Works that are Related with Student Model}

In the literature, there are several works related to the automatic detection of student learning styles $[7,8,9,10]$ and the detection of cognitive ability [11], through various computer tools. Nowadays, with the increase of techniques and tools for distance and virtual education, coupled with the growing interest in improving teaching - learning techniques, the generation of models for this purpose continues to emerge. In [11] the authors carry out a study that contributes to the mathematics and education research field by designing calculus tasks to be used as a measure of students' visual and analytic tendencies in calculus. Barron et al [10] also work with detection of learning styles and cognitive abilities through the development of an intelligent tutor system in which identify the emotional state of the student.

\subsection{Research Related to Cognitive Load Theory}

There are several investigations related to the cognitive load theory, however, within the context of the present investigation, are considered of utmost importance, those that are related, with experiments of the management of the cognitive load, in teaching-learning of mathematics [12, 13], as with the resolution of problems [14, 15, 13] and the management of computational tools $[16,17,18]$ that consider as base this theory. By example, in [14] a series of experiments related to the resolution of geometry problems is presented, in which the authors support the importance of having the students work with worked examples. The theory of cognitive load is also used in relation to multimedia, so in [19] conduct a study that identifies how multimedia 
interfaces can be developed that do not increase the cognitive load of students, thus preventing the inhibition of learning. Another work in which the authors emphasize the importance of the cognitive load in the teaching process is presented in [12], in which the results of an experiment with visual representations are showed.

\subsection{Papers Related to Assessment and / or Evaluation}

Although the topic of assessment or evaluation, in most research, are shown as a complementary part of other topics $[20,6,8,21,22]$ it is important to identify the strategies that are used for evaluation using automated tools. In [23] the authors argue that it is important to develop a form of evaluation that focuses on both the qualitative descriptions of the student's learning process and quantitative information.

\subsection{Instructional Design as Objective of some Research}

In learning mathematics, a proper instructional design can help the student construct a scheme that will allow him/her to store the information in long-term memory and in turn also help to avoid overloading working memory. An instructional design suitable for the teaching of mathematics could is to enable students to learn real-world problem solving in school mathematics [24, 13, 17, 25]. However, learning/teaching realworld problem solving in school mathematics occurs at different levels along two dimensions: student cognitive functioning and the extent to which teaching is explicit in mediating the real world. Based on this, in [24] propose four-level instructional objectives: 1) Identification, 2) Coordination, 3) Reflection and 4) Transformation.

\subsection{Teaching of Algebra}

There are several investigations related to the teaching of algebra, some included in projects related to computational tools [3, 26, 27, 28, 29], and others related to pedagogical models [30, 31, 32]. An example is the research carried out in [30], in which a model for classifying algebra problems based on three uses of the variable (as an unknown, as a general number and as a function), is used. With this model, the authors perform a comparative study of problem solving skills with these three uses of the variable, in students from Spain and Mexico. The advances of a project related to the management of video games and techniques of tutorial systems with artificial intelligence, to teach mathematical concepts of algebra are presented in [26].

\subsection{Problem Solving as a Topic of Study}

The issue of problem solving is very extensive, so there are several studies related to problem solving, which contemplate various strategies, as metacognition $[33,34,35$, 36] and heuristics [37], that have the purpose of analyzing mechanisms to improve the ability of students in this difficult task. Focusing the resolution of problems from metacognition, in the research carried out in [33] the authors conduct research to 
identify how metacognition, the beliefs of an individual related to solving mathematical problems and attitudes, affect the process of problem solving.

With regard to investigations that are related to the teaching of algebra and problem solving, reference can be made to the proposals of [38] and [3]. In the first, the authors develop an experiment based on a mathematical theme related to algebraic thinking and model the teaching of algebra using the problem solving approach. In the second the authors develop a cognitive tutor whom they call SimStudent, which has the ability to learn interactively from an expert model through the resolution of directed problems.

\subsection{Fuzzy Logic and Educational Systems}

In the educational context, models related to cognitive maps are used to generate tools related to the teaching - learning process $[39,6,40,5,41]$ due to their ability to simulate and predict causal behaviors related to students' learning behavior. In this way, in [39], the authors propose some new dimensions of adaptively like automatic and dynamic detection of learning styles and provides personalization accordingly. It is a literature-based approach in which a personalized adaptive learner model (PALM) was constructed.

\subsection{Some Papers on Human Computer Interaction}

Gamification and tangible user interfaces are two issues that are generating concerns, within the teaching - learning process, due to the question of whether the strategies used in games and the combination of non - virtual elements with the virtual, help or impair the performance of students in learning. In relation to the use of gamification in education, there are several applications that aim to assess how the gamification elements affect student satisfaction, motivation, enjoyment, learning potency, and degrees over time [42, 43, 26, 1, 27]. Regarding the use of tangible interfaces, in education, there are also several investigations focused on determining if the mixture of real interfaces with virtual systems can help improve the teaching-learning process $[44,45,46]$.

\section{$4 \quad$ Summary of Art State Analysis}

Finally, as a general synthesis, in Table 2, a list of papers from 2012 to date arranged chronologically are shown, these articles were selected because they include one or more of the topics analyzed in this paper, plus the main theme that has to see with Tutorial Systems. The first column of Table 2 (tagged with R) indicates the reference of the paper, the numbers of the other columns, organized as follows, indicate the topics in Table 1: 1. Tutorial Systems or learning environments. 2. Cognitive Load Theory or Cognitive Theory, 3. Assessment or evaluation, 4. Instructional Design o learning, 5. Algebra or Mathematics Teaching, 6. Problem Solving, 7. Feedback or Suggestions, 8. Human-Computer Interaction, 9. Student Model and 10. Fuzzy sys- 
tems or intelligent systems. After the column corresponding to item 10, a column was added indicating the impact of each paper, consulted in September 2017.

Table 2. Classification of papers based on the main topics related with the design of an CT.

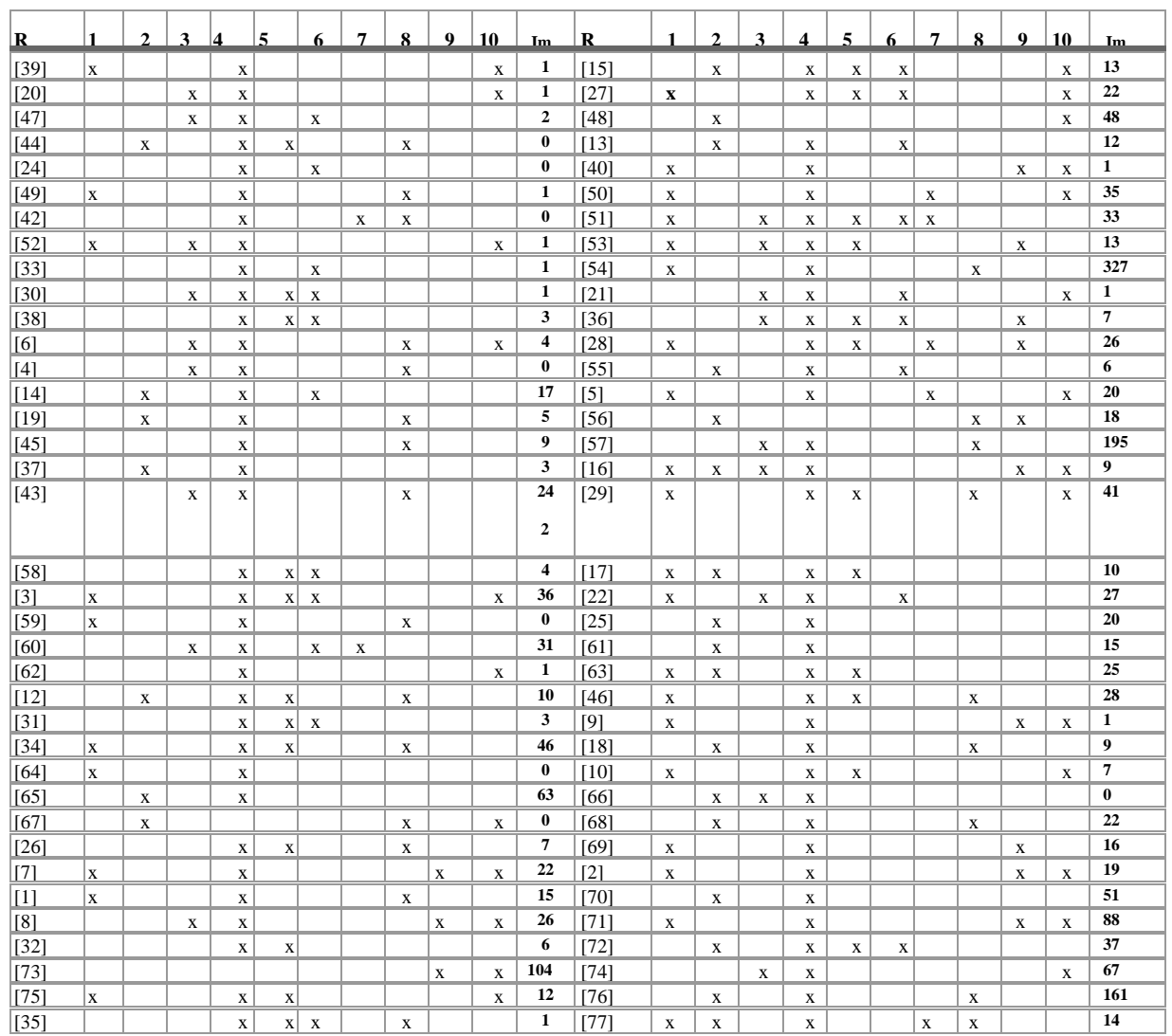

\subsection{Results of Analysis of Classification of Papers}

One of the main themes of this review of the state of the art is the ITS, but if we include the part of the pedagogical sustenance, the subject of CLT should be considered, analyzing the classification of Table 2 , it is observed that $40 \%$ of the articles have are related to ITS and $33 \%$ with the subject of CLT, but what really interesting to visualize the areas of opportunity in the development of ITS with cognitive pedagogical sustenance are the works that include these two themes, of which they are only $5 \%$, which means that there is a large area of opportunity to develop projects that include these two themes. One of the topics included in $95 \%$ of the articles is instructional design or teaching learning, evidently because the main applications of both ITS and CLT are related to teaching - learning. Regarding the topics that each article contains, the classification is as follows: $18 \%$ is related to 2 of the 10 topics, $35 \%$ with $3,33 \%$ with $4,11 \%$ with 5 and only $3 \%$ includes 6 of the 10 topics, that is, no 
paper considers more than 6 topics, so that developing research that includes $7,8,9$ or all themes are also areas of opportunity for future research projects.

\section{Conclusions}

An analysis of the conceptual topics related to the design and development of a cognitive tutor focused on the teaching of algebra has been conducted. The topics have been classified according to the module of the intelligent tutorial system to which they belong. A total of ten topics have been chosen, and a state of the art analysis has been conducted for each one of them.

We have been able to identify that some topics have been thoroughly studied, and that these studies are truly useful tools.

Regarding the modules that constitute a cognitive tutor, it has been observed that each one of them has its particular degree of difficulty due to the topics that have to be mastered. Nevertheless, according to the classification shown in Table 1, when the student model, domain model and tutor model modules are implemented, the cognitive tutor can be considered as implemented since the remaining modules are related to topics that have already been considered in the aforementioned modules.

Finally, the construction of a cognitive tutor requires from the designer and the developer an interdisciplinary formation, both in the knowledge field that will be the training object, and in artificial intelligence and computer science methods and techniques. All these factors pose a great challenge.

\section{References}

1. González, C., Mora, A., Toledo, P.: Gamification in intelligent tutoring systems. In: Proc. Second Int. Conf. Technol. Ecosyst. Enhancing Multicult. - TEEM '14, 221-225 (2014)

2. Fazel, M. H., Khademian, M., Minaei, B., Türkşen, I.B.: A Fuzzy Expert System Architecture for Intelligent Tutoring Systems: A Cognitive Mapping Approach. J. Intell. Learn. Syst. Appl., vol. 4, no. February, 29-40 (2012)

3. Matsuda, N., Cohen, W.W., Koedinger, K.R.: Teaching the teacher: Tutoring simstudent leads to more effective cognitive tutor authoring. Int. J. Artif. Intell. Educ., 25(1), 1-34 (2015)

4. Bossomaier, T.: Serious Games and Gaming, Vol 4, 201-232 (2015)

5. Chrysafiadi, K., Virvou, M.: A knowledge representation approach using fuzzy cognitive maps for better navigation support in an adaptive learning system. Springerplus, 2(1), 81-94 (2013)

6. Bolivar, H. B., González, R. C., Pascual, J. E., Sanjuán, O. M.: Assessment of learning in environments interactive through fuzzy cognitive maps. Soft Comput, 19, 1037-1050 (2015)

7. Feldman, J., Monteserin, A, Amandi, A.: Automatic detection of learning styles: state of the art. Artif. Intell. Rev., no. May 2014, 157-186 (2014)

8. Jegatha, L. D., Baskaran, R., Kannan, A.: Learning styles assessment and theoretical origin in an E-learning scenario: a survey. Artif. Intell. Rev., 42(4), 801-819 (2014)

9. Zatarain, R. C., M., Barrón, L. E., Olivares, L. C., Reyes, C. G.: Integrating learning styles 
and affect with an intelligent tutoring system. Proc. - 2013 12th Mex. Int. Conf. Artif. Intell, MICAI 2013, 247-253 (2013)

10. Barron., L. E., Zatarain, R. C., Beltrán, J. V., Cibrian, F. R., Hernández, Y. P.: An Intelligent and Affective Tutoring System within a Social Network for Learning Mathematics. 651-661 (2012)

11. Haciomeroglu, E. S.: The role of cognitive ability and preferred mode of processing in students' calculus performance. Eurasia J. Math. Sci. Technol. Educ., 11(5), 1165-1179 (2015)

12. Yung, H., Paas, F.: Effects of computer-based visual representation on mathematics learning and cognitive load. Educ. Technol. Soc., 18(4), 70-77 (2015)

13. Ngu, B. H, A. Yeung, A. S., Tobias, S.: Cognitive load in percentage change problems: Unitary, pictorial, and equation approaches to instruction. Instr. Sci., 42(5), 685-713 (2014)

14. Chen, O., Kalyuga, S., Sweller, J.: The worked example effec, the generation effect and element interactivity. J. Educ. Psychol., 107(3), 689-704 (2015)

15. Lin J. J., Lin, S. S.: Cognitive Load for Configuration Comprehension in Computer-Supported Geometry Problem Solving: An Eye Movement Perspective. Int. J. Sci. Math. Educ., 12 (3), 605-627 (2014)

16. Lach, P.: Student's Effort During Assessment. 346-351 (2013)

17. Reed, S. K., Corbett, A., Hoffman, B., Wagner, A., MacLaren, B.: Effect of worked examples and Cognitive Tutor training on constructing equations. Instr. Sci., 41(1), 1-24 (2013)

18. Andrade-Lotero, L. A.: Teoría de la carga cognitiva, diseño multimedia y aprendizaje: Un estado del arte. Magis, 5(10), 75-92 (2012)

19. Cheng, T. S., Lu, Y. C., Yang, C. S.: Using the multi-display teaching system to lower cognitive load. Educ. Technol. Soc., 18(4), 128-140 (2015)

20. Goksu, I.: The Evaluation of the Cognitive Learning Process of the Renewed Bloom Taxonomy Using a Web Based Expert System. 15(4), 135-152 (2016)

21. Sharma, M., Chawla, S.: A Tools for Creating Constructivist Learning Environment and Assessing Knowledge Development using Concept Maps. 5(8) (2014)

22. Reimann, P., Kickmeier-Rust, M., Albert, D.: Problem solving learning environments and assessment: A knowledge space theory approach. Comput. Educ., 64, 183-193 (2013)

23. Hassan, O. B.: Learning theories and assessment methodologies - an engineering educational perspective. Eur. J. Eng. Educ., vol. 36, no. March 2015, 327-339 (2011)

24. Jurdak, M.: Learning and Teaching Real World Problem Solving in School Mathematics. 181-195 (2016)

25. Rey, G. D., Andreas, F.: The expertise reversal effect concerning instructional explanations. Instr. Sci., 41(4), 635-656 (2013)

26. Faghihi, U., Brautigam, A., Jorgenson, K., Martin, D., Brown, A., Measures, E.: Maldonado-Bouchard, S.: How gamification applies for educational purpose specially with college algebra. Procedia Comput. Sci., 41, 182-187 (2014)

27. Long, Y., Aleven, V.: Gamification of Joint Student/System Control Over Problem Selection in a Linear Equation Tutor. Science (80-87), 37, 849-874 (2014)

28. Walker, E., Rummel, N., Koedinger, K. R.: Adaptive intelligent support to improve peer tutoring in algebra. Int. J. Artif. Intell. Educ., 24(1), 33-61 (2014)

29. Mavrikis, M., Noss, R., Hoyles, C., Geraniou, E.: Sowing the seeds of algebraic generalization: Designing epistemic affordances for an intelligent microworld. J. Comput. Assist. Learn., 29(1), 68-84 (2013)

30. Álvarez, I., Gomez-Chacón, I. Ursini, S.: Understanding the Algebraic Variable: comparative Study of Mexican and Spanish Students. 11(6), 1507-1529 (2015) 
31. Zeljić, M.: Modelling the Relationships Between Quantities: Meaning in Literal Expressions. 11(2), 431-442 (2015)

32. Jupri, A., Drijvers, P., Heuvel-Panhuizen, M.: Student difficulties in solving equations from an operational and a structural perspective. Int. Electron. J. Math. Educ., 9(1-2), 39-55 (2014)

33. Bas, F., Sagirli, M.: The Metacognitive Awarenesses of Pre- Service Secondary School Mathematics Teachers, Beliefs, Attitudes on Problem Solving, and Relationship Between Them. 12(2), 464-482 (2016)

34. Arroyo, I., Woolf, B. P. Burelson, W., Muldner, K., Rai, D., Tai, M.: A multimedia adaptive tutoring system for mathematics that addresses cognition, metacognition and affect. Int. J. Artif. Intell. Educ., 24(4), 387-426 (2014)

35. Kramarski, B., Friedman, S.: Solicited versus Unsolicited Metacognitive Prompts for Fostering Mathematical Problem Solving Using Multimedia. J. Educ. Comput. Res., 50(3), 285-314 (2014)

36. Tzohar-Rozen, M., Kramarski, B.: Metacognition, Motivation and Emotions: Contribution of Self-Regulated Learning to Solving Mathematical Problems. Glob. Educ. Rev., 1(4), 76-95 (2014)

37. Eisenmann, P., Novotná, J., Přibyl, J., Břehovský, J.: The development of a culture of problem solving with secondary students through heuristic strategies. Math. Educ. Res. J., 27, (4), 535-562 (2015)

38. Bailey, J., Taylor, M.: Experiencing a mathematical problem-solving teaching approach: Opportunities to identify ambitious teaching practices. 17, 111-124 (2015)

39. Sweta, S., Lal, K.: Personalized Adaptive Learner Model in E-Learning System Using FCM and Fuzzy Inference System. Int. J. Fuzzy Syst. (2017)

40. Peña-Ayala, A., Sossa-Azuela, J. H.: Decision Making by Rule-Based Fuzzy Cognitive Maps: An Approach to Implement Student-Centered Education. Fuzzy Cogn. Maps Appl. Sci., 54, 107-120 (2014)

41. Zouhair, A., En-Naimi, E. M., Amami, B., Boukachour, H., Person, P., Bertelle, C.: Intelligent tutoring systems founded on the multi-agent incremental dynamic case based reasoning. Cist 2012 - Proc. 2012 Colloq. Inf. Sci. Technol., 74-79 (2012)

42. Mozelius, P., Fagerström, A., Söderquist, M.: Motivating Factors and Intrinsic Integration of Knowledge in Educational Games. Eur. Conf. Games Based Learn., 500-508 (2016)

43. Hanus, M. D., Fox, J.: Assessing the effects of gamification in the classroom: A longitudinal study on intrinsic motivation, social comparison, satisfaction, effort, and academic performance. Comput. Educ., 80. 152-161 (2015)

44. Guerrero, G., Ayala, A., Mateu, J., Casades, L., Alamán, X.: Integrating Virtual Worlds with Tangible User Interfaces for Teaching Mathematics: A Pilot Study. Sensors, 16(11), 1775 (2016)

45. Cuendet, S., Dehler-Zufferey, J., Ortoleva, G., Dillenbourg, P.: An integrated way of using a tangible user interface in a classroom. Int. J. Comput. Collab. Learn., 10(2) 183-208 (2015)

46. Starcic, A., I., Cotic, M., Zajc, M.: Design-based research on the use of a tangible user interface for geometry teaching in an inclusive classroom geometry teaching in an inclusive classroom. 44(5), 729-745 (2013)

47. Grover, S., Bienkowski, M., Niekrasz, J., Hauswirth, M.: Assessing Problem-Solving Process a t Scale. 245-248 (2016)

48. Gray, S. A., Zanre, E., Gray, S. R..: Fuzzy Cognitive Maps for Applied Sciences and Engineering. Intell. Syst. Ref. Libr. 54, 159-175 (2014)

49. Millis, K., Forsyth, C., Wallace, P., Graesser, A., Timmins, G.: The Impact of Game-Like 
Features on Learning from an Intelligent Tutoring System. Technol. Knowl. Learn., 22(1) 1-22 (2016)

50. Rivers, K., Koedinger, K., R.: Automating Hint Generation with Solution Space Path Construction. 329-339 (2014)

51. Roll, I., Baker, R., Aleven, V., Koedinger, K., R.: On the Benefits of Seeking (and Avoiding) Help in Online Problem-solving Environments. J. Learn. Sci., 23(4), 537-560 (2014)

52. Ramirez-Noriega, A., Reyes, J. R., Martinez-Ramirez, Y., Jimenez, S., Inzunza, S.: Using Bayesian Networks for Knowledge Representation and Evaluation in Intelligent Tutoring Systems. Data Min. Acad. Databases, (2), 189-198 (2016)

53. San Pedro, M. O., Baker, R., Rodrigo, M. M.: Carelessness and affect in an intelligent tutoring system for mathematics. Int. J. Artif. Intell. Educ. 24(2), 189-210 (2014)

54. Seaborn, K., Fels, D. I.: Gamification in theory and action: A survey. Int. J. Hum. Comput. Stud., 74, 14-31 (2014)

55. Alzahrani, I., Woollard, J.: The Role of the Constructivist Learning Theory and Collaborative Learning Environment on Wiki Classroom, and the Relationship between Them. Online Submiss (2013)

56. Francisco-Aparicio, a., Gutiérrez-Vela, F. L., Isla-Montes, J. L., González-Sánchez, J. L: Gamification: Analysis and Application. 45-61 (2013)

57. Kulkarni, C., Papadopoulos, K., Cheng, J., Koller, D., Klemmer, S. R.: Peer and Self-Assessment in Massive Online Classes. 20(6) (2013)

58. Hong, J. Y., Kim, M. K.: Mathematical Abstraction in the Solving of Ill-Structured Problems by Elementary School Students in Korea. EURASIA J. Math. Sci. Technol. Educ., 12(2), 267-281 (2015)

59. Mukhtar, H.: Conceptual Model to Incorporate Serious Games Mechanics in Intelligent Tutoring Systems. 5, 13-18 (2016)

60. Piech, C., Huang, J., Sahami, M., Guibas, L.: Autonomously generating hints by inferring problem solving policies. 195-204 (2015)

61. Roelle, J., Berthold, K.: The expertise reversal effect in prompting focused processing of instructional explanations. Instr. Sci., 41(4), 635-656 (2013)

62. Bodyanskiy, Y. V., Tyshchenko, O. K., Deineko, A. O.: An Evolving Neuro-Fuzzy System with Online Learning/Self-learning. Int. J. Mod. Educ. Comput. Sci., 7(2), 1-7 (2015)

63. Schwonke, R., Ertelt, A., Otieno, C., Renkl, A., Aleven, V., Salden, R. J.: Metacognitive support promotes an effective use of instructional resources in intelligent tutoring. Learn. Instr., 23(1), 136-150 (2013)

64. Caro, M. F., Jimenez, J. A.: MOF-based metamodel for pedagogical strategy modeling in Intelligent Tutoring Systems. In: 2014 9th Computation Colomb. Conferences 9CCC 2014, 1-6 (2014)

65. Choi, H. H., VanMerriënboer, J. J., Paas, F.: Effects of the Physical Environment on Cognitive Load and Learning: Towards a New Model of Cognitive Load. Educ. Psychol. Rev., 26(2), 225-244 (2014)

66. Chen, Y.: Assessment System based on Scaffolding and Bloom's Theory. J. Digit. Content Technol. its Appl., 6(6), 218-227 (2012)

67. Conde-ram, J. C., Abraham, S.: Evocación de hábitos en personajes virtuales mediante Mapas Cognitivos Difusos y técnicas de videojuegos. 73, 73-87 (2014)

68. Cheon, J., Grant, M. M.: The effects of metaphorical interface on germane cognitive load in Web-based instruction. Educ. Technol. Res. Dev., 60(3), 399-420 (2012) 
69. Dung, P. Q., Florea, A. M.: A literature-based method to automatically detect learning styles in learning management systems. In: Proc. 2nd Int. Conf. Web Intell. Min. Semant. WIMS '12, 1 (2012)

70. Kalyuga, S., Rikers, R., Paas, F.: Educational Implications of Expertise Reversal Effects in Learning and Performance of Complex Cognitive and Sensorimotor Skills. Educ. Psychol. Rev., 24(2), 313-337 (2012)

71. Latham, A., Crockett, K., McLean, D., Edmonds, B.: A conversational intelligent tutoring system to automatically predict learning styles. Comput. Educ., 9(1), 95-109 (2012)

72. Leppink, J., Broers, N. J., Imbos, T., vanderVleuten, C. P., Berger, M. P.: Self-explanation in the domain of statistics: An expertise reversal effect. High. Educ., 63(6), 771-785 (2012)

73. Kar, S., Das, S., Ghosh, P. K.: Applications of neuro fuzzy systems: A brief review and future outline. Appl. Soft Comput., 15, 243-259 (2014)

74. Mislevy, R. J., Behrens, J. T., Dicerbo, K. E., Levy, R.: Design and discovery in educational assessment: Evidence-centered design, psychometrics, and Educational Data Mining. J. Educ. Data Min., 4(1), 11-48 (2012)

75. Khachatryan, G. A., Romashov, A. V., Khachatryan, A. R., Gaudino, S. J., Khachatryan, J. M., Guarian, K. R., Yufa, N. V.: Reasoning mind genie 2: An intelligent tutoring system as a vehicle for international transfer of instructional methods in mathematics. Int. J. Artif. Intell. Educ., 24(3), 333-382 (2014)

76. Paas, F., Sweller, J.: An Evolutionary Upgrade of Cognitive Load Theory: Using the Human Motor System and Collaboration to Support the Learning of Complex Cognitive Tasks. Educ. Psychol. Rev., 24(1), 27-45 (2012)

77. Paquette, L., Lebeau, J. F., Andre, M.: Automating Next-Step Hints Generation Using ASTUS. Springer- Verlag Berlin Heidelberg, 201-211 (2012) 